Article

\title{
Experimental Analysis of Tribological Processes in Friction Pairs with Laser Borided Elements Lubricated with Engine Oils
}

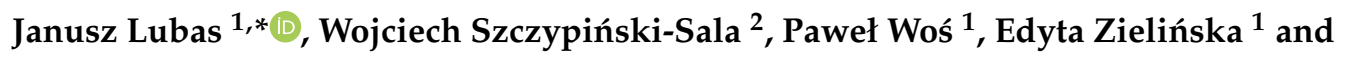 \\ Krzysztof Miernik ${ }^{3}$ \\ 1 Faculty of Mechanical Engineering and Aeronautic, Rzeszow University of Technology, \\ Powstańców Warszawy 8, 35-959 Rzeszów, Poland; pwos@prz.edu.pl (P.W.); ezielins@prz.edu.pl (E.Z.) \\ 2 Faculty of Mechanical Engineering, Cracow University of Technology, al. Jana Pawła II 37, 31-864 Cracow, \\ Poland; ws@mech.pk.edu.pl \\ 3 Faculty of Materials Engineering and Physics, Cracow University of Technology, al. Jana Pawła II 37, \\ 31-864 Cracow, Poland; kmiernik@pk.edu.pl \\ * Correspondence: lubasj@prz.edu.pl
}

Received: 17 October 2020; Accepted: 16 December 2020; Published: 19 December 2020

\begin{abstract}
The present study discusses the influence of engine oils on the tribological parameters of sliding couples with laser borided surface layer. The borided layer was formed on specimens made from AISI 5045 steel by laser remelting of a surface layer coated with amorphous boron. The sliding friction and wear process was carried out on the pairs with AISI 5045 steel and SAE-48 bearing alloys which were lubricated with $5 \mathrm{~W}-40$ and $15 \mathrm{~W}-40$ engine oils. The investigation showed significant differences in the friction coefficient and temperature in the tested pairs with the laser borided surface layer. In the couples lubricated with $5 \mathrm{~W}-40$ engine oil, the tested parameter of friction was higher than in the couples lubricated with $15 \mathrm{~W}-40$ engine oil. The couples lubricated with $5 \mathrm{~W}-40$ engine oil showed more intensive wear of SAE-48 bearing alloy in contact with the laser borided surface layer than the pairs lubricated with $15 \mathrm{~W}-40$ engine oil. The laser borided surface layer used in friction pairs leads to the destruction of the lubricating properties of engine oils and reduces its resistance to scuffing.
\end{abstract}

Keywords: laser boriding; engine oil; wear; friction; surface layer

\section{Introduction}

The structural elements of machines are subjected to various unfavorable operating factors that shorten their service life, which, in turn, affects the reliability of the entire structure. The friction pairs used in internal combustion engines are exposed to an intensive destruction processes caused by the abrasive wear, adhesion, oxidation and cavitation processes. The intensity of these processes is influenced by the structure of the friction pair, materials of the friction elements, surface treatment, loading and lubrication conditions.

In the currently used constructions of friction pairs, friction and wear are the result of appropriate shaping of the contacting surface layers. In the case of most components operating under frictional conditions, a surface layer of high hardness and wear resistance is required. Sometimes, they also require increased fatigue resistance, corrosion resistance, heat resistance and creep resistance. One of the surface treatment methods which enables the formation of the required structure of the surface layer of constructional elements operating under friction conditions is laser treatment [1-6]. The surface layers produced in this way show favorable tribological properties in the form of the required hardness, fracture toughness, abrasion resistance and corrosion resistance [7-15]. Improving the microstructure 
of surface layers and coatings is also mentioned as one of the advantages of using laser techniques in surface treatment $[14,16,17]$. The study of wear of the laser-treated steel shows lower values of friction coefficients and lower wear of samples [18,19].

One of the elements that can be used in the laser remelting process is boron. This element forms stable and hard phases with iron, and laser treatment allows to eliminate the textured, coniferous structure of the surface layer $[2,14,20,21]$. Other authors indicate that this process also provides a lower coefficient of friction, good oxidation and resistance to erosion $[14,20,22]$. Boron content in the laser treatment steel layer significantly reduces the wear under dry friction conditions [15,22-24]. Tests in dry sand/rubber wheel conditions showed that the abrasive wear of $\mathrm{Fe}_{50} \mathrm{Mn}_{30} \mathrm{Co}_{10} \mathrm{Cr}_{10}$ was reduced by up to $30 \%$ compared to the material without laser treatment [22]. The results of EN25 steel tests showed that laser boriding increases corrosion resistance and causes uniform corrosion of the surface of the test sample, which results from the formation of iron borides during laser processing $[20,22]$. However, some authors indicate that replacing diffusion drilling in the case of elements requiring high fatigue strength by laser drilling is not recommended [24].

The surface cracks occurring after laser remelting are then the cause of the fatigue crack. In the case of laser borided carbon steels, the carbon content influences the heating and cooling of the material. It has been shown that higher concentration of carbon in the laser borided steel influences the increase in peak temperature and cooling rate, and also increases the depths of re-melted zone and heat-affected zone [25]. The process of boriding nickel alloys is difficult when using classical methods or requires the use of proprietary boriding agents [26]. The use of the laser beam allows the melting of the boron layer and the creation of a boron zone consisting of iron, nickel and chromium borides. The hardness of this layer is comparable to that obtained in the case of diffusion drilling, with its much greater thickness (346 or $467 \mu \mathrm{m}$ depending on the power of the laser used) [27-29]. Laser boriding of nickel alloy increases its wear resistance, which may be ten times higher compared to the untreated material $[26,27,29]$.

Although real components usually work in a mixed lubrication mode [30], most publications limit the scope of their research to abrasive wear [15,19,21,22]. Garcia et al. [31] showed that partially laser remelted surfaces of plasma spray coatings reduce wear only under certain pressures and sliding velocities. Moreover, they observed that higher percentage of the remelted surface may cause inadequate lubrication conditions and increase the wear of elements [31,32]. Most friction pairs require lubrication, it is important to determine the influence of laser remelting for tribological processes under limited lubrication conditions.

The aim of the present study is to investigate the influence of the selected classes of engine oils on friction and wear processes in friction pairs containing elements with laser borided surface layer. The use of boriding causes the formation of hard borides, which are resistant to wear, and the use of laser boriding assures that surface layer does not show a tendency to crack. Such surface layers can be used in friction pairs in internal combustion engines lubricated with $5 \mathrm{~W}-40$ and $15 \mathrm{~W}-40$ engine oils. This requires an answer to the question of what is the influence of engine oils on tribological processes under limited lubrication conditions. This paper also describes the anti-seizure parameters of the engine oils used for lubrication of the sliding pairs with elements containing boron.

\section{Materials and Methods}

AISI 5045 steel is widely used in mechanical engineering, including the construction of heavily loaded elements in internal combustion engines (Table 1). AISI 5045 steel ring samples with dimensions of $\phi 35 \times 9 \mathrm{~mm}$ were prepared and were heat-treated $(40 \pm 2)$ and polished (Figure 1). The boron layer was produced by a $\mathrm{CO}_{2}$ laser with a power of $2 \mathrm{~kW}$. Steel samples were covered with mixed amorphous boron with water glass and fused with a laser beam to protect argon. The laser treatment parameters used in the surface layer remelting process were determined by the spot size of the laser beam of $4 \mathrm{~mm}$, the processing speed of $16 \mathrm{~mm} / \mathrm{s}$ and the path coverage of $0.5 \mathrm{~mm}$. After the laser treatment, the surface layer of steel samples was polished. The counterpart was cut from the the 
SAE-48 alloy journal bearing (Tables 1 and 2) with dimensions of $15.75 \times 6.35 \mathrm{~mm}$ (Figure 1). As a result of the laser treatment, a boron layer was produced with a content of $1-1.5 \%$ boron, a maximum thickness of $25 \mu \mathrm{m}$ and a maximum hardness of $1800 \mathrm{HV}$ (Figure 2).

Tribological comparative studies were carried out in a conformal contact with the lubrication of the friction area with the engine oil, which is widely used for lubrication of petrol and diesel engines of passenger cars and delivery vans, working with and without turbochargers that require this level of quality (Table 3).

Table 1. Chemical composition of specimens (wt.\%).

\begin{tabular}{cccccccc}
\hline Material & C & Cr & Mn & Si & Fe & Pb & Cu \\
\hline AISI 5045 & 0.46 & 0.5 & 0.65 & $<0.4$ & Balance & - & - \\
\hline SAE-48 & - & - & - & & - & $26-33$ & Balance \\
\hline
\end{tabular}

Table 2. Mechanical properties of SAE-48 bearing alloy ( $\mathrm{CuPb} 30)$.

\begin{tabular}{lc}
\hline Operating temperature Tmax $\left({ }^{\circ} \mathrm{C}\right)$ & 170 \\
\hline Load Pmax $\left(\mathrm{N} / \mathrm{mm}^{2}\right)$ & 140 \\
\hline Tensile Strength $\left(\mathrm{N} / \mathrm{mm}^{2}\right)$ & 200 \\
\hline Sliding Speed V-oil Lubricated $(\mathrm{m} / \mathrm{s})$ & 8 \\
\hline Alloy Hardness $(\mathrm{HB})$ & $30-45$ \\
\hline
\end{tabular}

Table 3. Characteristics of engine oils.

\begin{tabular}{ccc}
\hline Parameter & $\mathbf{5 W - 0}$ Synthetic Oil & $\mathbf{1 5 W}-\mathbf{4 0}$ Mineral Oil \\
\hline Kinematic Viscosity at $100{ }^{\circ} \mathrm{C}$ & $13.7 \mathrm{~mm}^{2} / \mathrm{s}$ & $14.5 \mathrm{~mm}^{2} / \mathrm{s}$ \\
Viscosity Index & 178 & 133 \\
HTHS Dynamic Viscosity at $150{ }^{\circ} \mathrm{C}$ & $3.6 \mathrm{mPa} \cdot \mathrm{s}$ & $3.8 \mathrm{mPa} \cdot \mathrm{s}$ \\
Specification & API-SL/SJ/CF/CD & API SJ/CF \\
& ACEA-A3-98/B3-98/B4-98 & ACEA A3-02/B3-98 \\
\hline
\end{tabular}
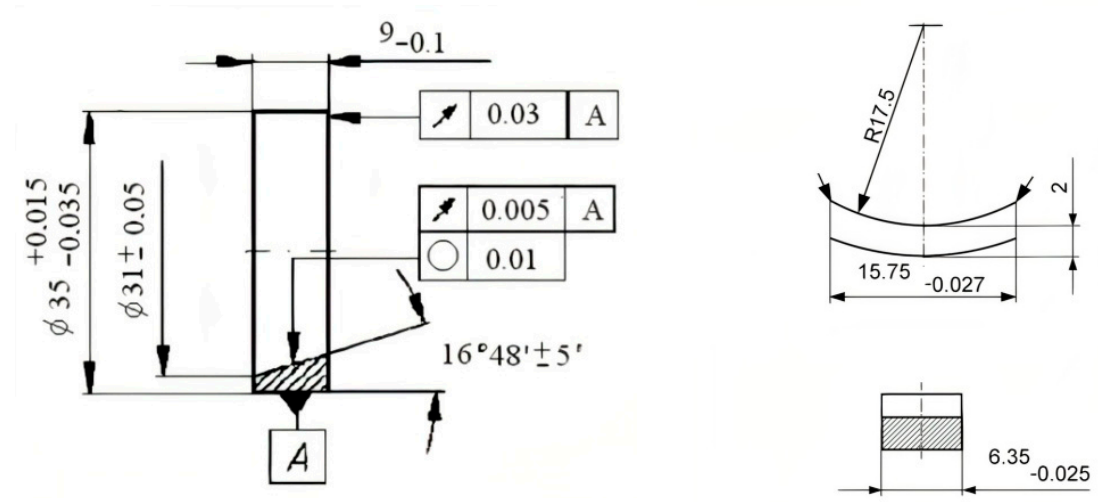

Figure 1. Dimensions of elements of the tested pair (mm). 


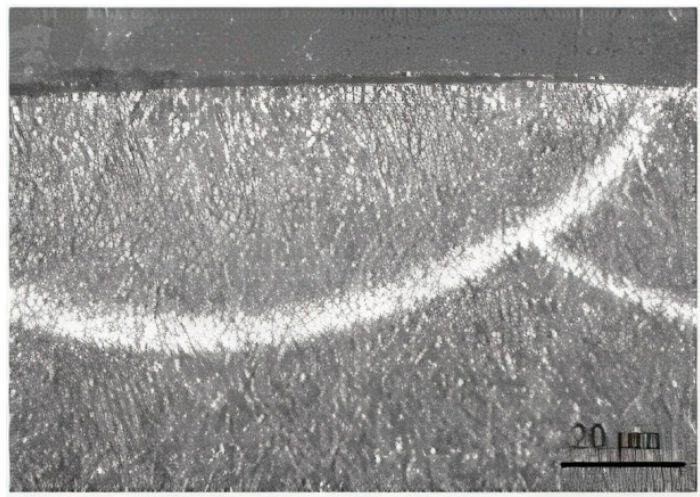

Figure 2. Microstructure of the steel specimen with laser borided surface layer.

The measurements of the friction pair co-operating under lubrication conditions were taken at the ring specimen rotational speed of $100 \mathrm{rpm}$ and at a changeable unit pressure of 5, 10, 15 and $20 \mathrm{MPa}$. The measured parameters, such as friction coefficient, temperature in the friction area and linear wear as a function of changeable load were registered at real-time during the tests. The tribological tests were conducted on the T- 05 block on ring tester (Figure 3) and the steel specimen was immersed in lubricants (engine oils) (Figure 3).

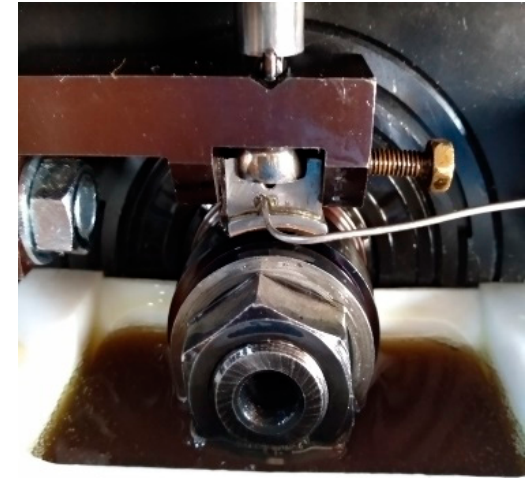

(a)

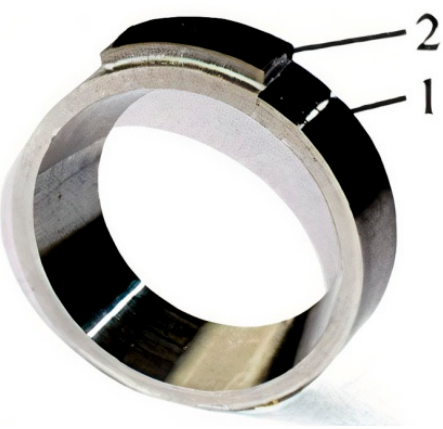

(b)

Figure 3. The friction pair in block on ring tester (a) and composition of friction pair: 1-ring specimen, 2-counterpart (b).

Scuffing test of engine oils in the sliding movement was performed utilizing the four-ball testing machine. In the tests, the balls with a diameter of $12.7 \mathrm{~mm}(0.5 \mathrm{in}$.) were used. The surface roughness, expressed as Ra parameter equaled $0.032 \mu \mathrm{m}$, and hardness amounted to $62 \mathrm{HRC} \pm 2$. All tests during the current research were repeated three times.

\section{Results}

The measurements of surface roughness of the borided ring samples and counterparts with the bearing alloy after tests revealed significant changes, as compared to the roughness prior to the tests. The measurements of the $\mathrm{Ra}, \mathrm{Rz}$ and Sm parameters of surface roughness indicated an increase of surface roughness. The measurements of Ra parameter of ring specimens showed the change of $3 \%$ in the pairs lubricated with synthetic oil and $7 \%$ in the pairs lubricated with mineral oil (Table 4).

Changes of a similar character, but on a much larger scale occurred in the case of the measurement of the Sm parameter, which increased by $62 \%$ in the friction pairs lubricated with the $15 \mathrm{~W}-40$ mineral oil, and by $49 \%$ in those lubricated with the $5 \mathrm{~W}-40$ synthetic oil. When measuring the Rz parameter, lubrication with the $15 \mathrm{~W}-40$ engine oil caused smaller changes in the geometric structure of the surface $(19 \%)$ than in the case of using the $5 \mathrm{~W}-40$ engine oil $(26 \%)$. 
Table 4. Roughness of steel ring specimens after the test under pressure of $20 \mathrm{MPa}$ (DIN 4768, ISO 4287).

\begin{tabular}{ccccc}
\hline Engine Oil & \multicolumn{2}{c}{$5 \mathbf{W}-40$ Synthetic Oil } & \multicolumn{2}{c}{$\mathbf{1 5 W}-\mathbf{4 0}$ Mineral Oil } \\
\hline Parameter & Value $[\boldsymbol{\mu m}]$ & Change $[\%]$ & Value $[\boldsymbol{\mu m}]$ & Change $[\%]$ \\
Ra & 0.31 & 3 & 0.32 & 7 \\
Rz DIN & 3.4 & 26 & 3.2 & 19 \\
Sm & 82 & 49 & 89 & 62 \\
\hline
\end{tabular}

The surface roughness of the counterparts from SAE- 48 bearing alloy showed more extensive changes in the measured parameters than of ring specimens with laser borided layer (Table 5). The changes of $\mathrm{Ra}, \mathrm{Rz}$ and Sm parameters of the counterparts exceeded even several dozen percent. The $15 \mathrm{~W}-40$ mineral oil lubrication showed smaller percentage changes in surface roughness, as opposed to lubrication with the $5 \mathrm{~W}-40$ synthetic oil. Particularly significant changes relate to the Sm parameters, which in the friction pairs lubricated with mineral oil increased by $156 \%$ and with synthetic oil by $192 \%$. Minor changes were observed for the Rz parameter and were $83 \%$ and $137 \%$, respectively. The Ra parameter was increased by $44 \%$ in the pairs lubricated with mineral oil and by $78 \%$ in those lubricated with synthetic oil.

Table 5. Roughness of counterparts from SAE-48 after the test under pressure 20 MPa (DIN 4768, ISO 4287).

\begin{tabular}{ccccc}
\hline Engine Oil & \multicolumn{2}{c}{$\mathbf{5 W}-\mathbf{4 0}$ Synthetic Oil } & \multicolumn{2}{c}{$\mathbf{1 5 W}-40$ Mineral Oil } \\
\hline Parameter & Value $[\boldsymbol{\mu m}]$ & Change $[\%]$ & Value $[\boldsymbol{\mu m}]$ & Change $[\%]$ \\
\hline Ra & 0.89 & 78 & 0.72 & 44 \\
Rz DIN & 7.1 & 137 & 5.5 & 83 \\
Sm & 140 & 192 & 123 & 156 \\
\hline
\end{tabular}

During the start-up of the friction pair, the registration of the friction coefficient allows for the determination of the energy demand necessary to start the friction pair, specification of frictional resistance in variable sliding conditions and their stabilization areas depending on the load conditions. An important parameter characterizing kinematic pairs is the maximum moment of friction during start-up of the tested friction pairs. In the tested pairs with a boron surface layer, the start-up moment was lower when lubricating the friction area with mineral oil than when lubricating it with synthetic oil (Figure 4). An important change is observed in the entire tested load range from 5 to $20 \mathrm{MPa}$. A significant difference in the start-up moment of the friction pair is observed at a load of $10 \mathrm{MPa}$, which is then $22 \%$. Smaller difference is observed at the lowest load of $5 \mathrm{MPa}$ and then the difference does not exceed $15 \%$. At loads of $15-20 \mathrm{MPa}$, the start-up moment value is similar for both tested engine oils and does not exceed $3 \%$.

The changes of friction resistance in the friction pairs with the laser borided surface layer in the start-up period showed a lower friction coefficient in pairs lubricated with the $5 \mathrm{~W}-40$ synthetic oil than in pairs lubricated with the $15 \mathrm{~W}-40$ mineral oil (Figure 5). For loads of 10-20 MPa, after the initial increase in the friction coefficient at the moment of start-up of the friction pair, a further increase in the friction resistance is observed along with the duration of the test. The value of the friction coefficient stabilizes only at a load of $5 \mathrm{MPa}$. In the pairs lubricated with mineral engine oil, at the load of $15-20 \mathrm{MPa}$, the course of the friction coefficient is similar and reaches similar values for all three tested loads, so that in the final stage of the test, the coefficient value is about 0.17 . At the load of $15 \mathrm{MPa}$, the friction coefficient stabilizes at the level of 0.15 . The variable course of the friction coefficient at the load of $5 \mathrm{MPa}$, in the initial phase of cooperation of the friction pair, leads to its stabilization after $350 \mathrm{~s}$, at the level of 0.12 . Under lubrication conditions with synthetic oil, at the loads of $10-20 \mathrm{MPa}$, there is a systematic increase in the value of the friction coefficient to its final value of 0.13 for the load of $10 \mathrm{MPa}$, 
0,14 for $15 \mathrm{MPa}$, and over 0.15 for $20 \mathrm{MPa}$. At the lowest load of $5 \mathrm{MPa}$, the friction coefficient stabilizes below 0.09 , after less than $100 \mathrm{~s}$.

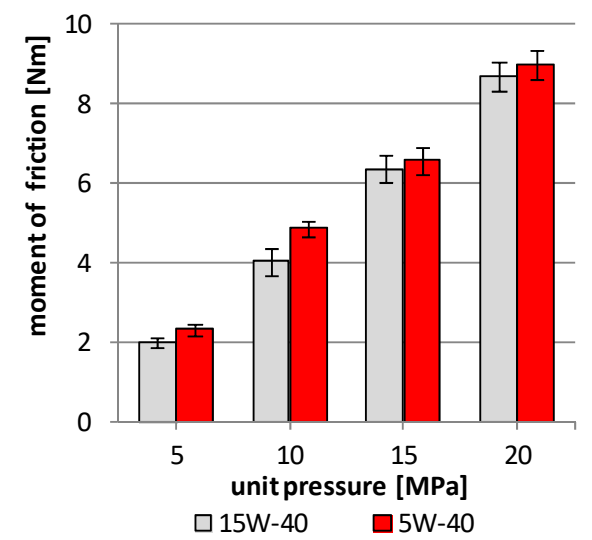

Figure 4. Moment of friction during start-up of the pair vs unit pressure when lubricating with $15 \mathrm{~W}-40$ mineral engine oil and 5W-40 synthetic engine oil.

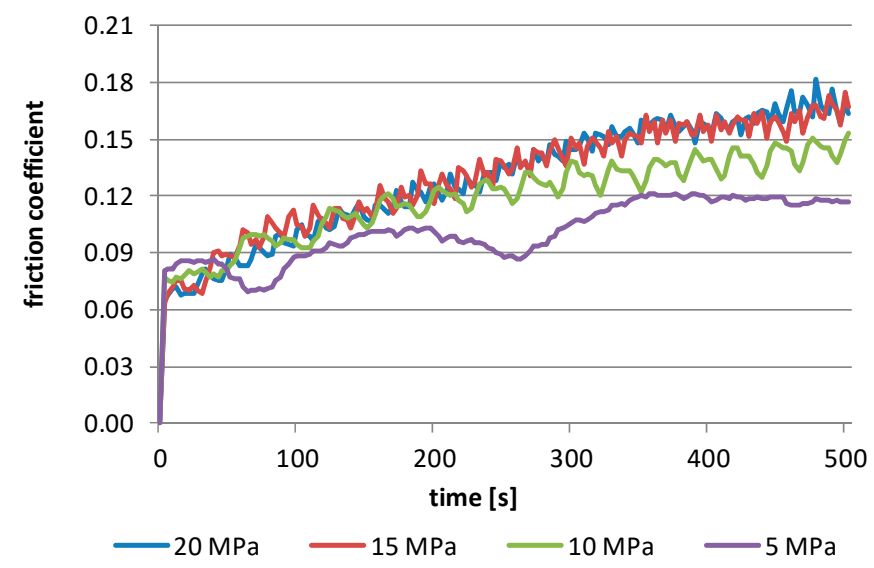

(a)

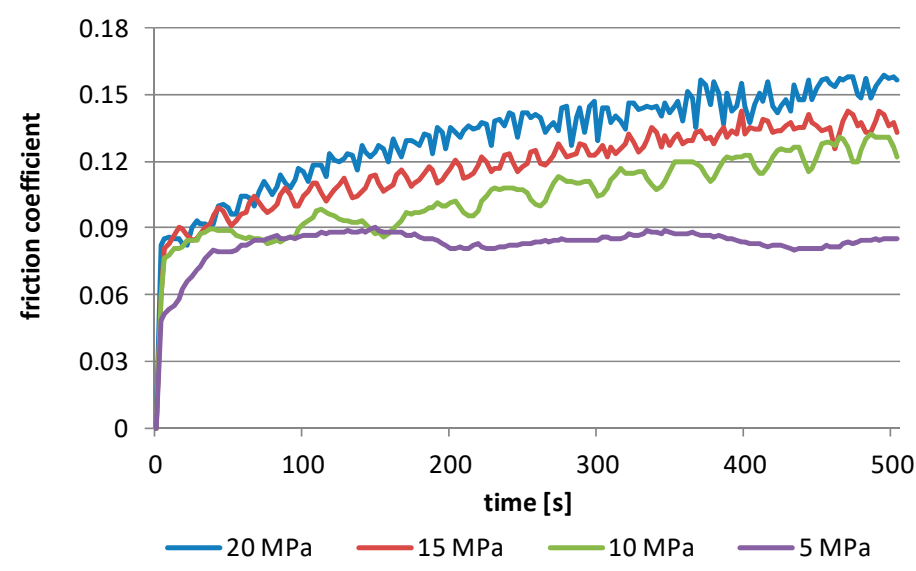

(b)

Figure 5. Friction coefficient in a sliding couple with laser borided surface layer vs rotation speed, lubricated with (a) 15W-40 mineral engine oil, (b) 5W-40 synthetic engine oil. 
The friction force and temperature in the friction area allows to determine the working conditions of the friction pair, and if they show lower values, such a system ensures greater stability of operation and greater safety area in the event of an overload of the friction pair, which may lead to its seizure and destruction.

The friction force and temperature in the friction area for the pairs lubricated with the $15 \mathrm{~W}-40$ mineral oil are higher than in the case of the pairs lubricated with the $5 \mathrm{~W}-40$ synthetic oil (Figure 4). The greatest difference in the friction force occurs at the load of $5 \mathrm{MPa}$ of the friction pair and it is $19 \%$ lower for the pair lubricated with the $5 \mathrm{~W}-40$ oil, as compared to the pair lubricated with $15 \mathrm{~W}-40$ oil. In the case of the remaining loads of 10-20 MPa, the difference amounts to a few percent, and in the case of the $15 \mathrm{MPa}$ load, the difference is $2 \%$, which is within the limits of the measurement method. The measured temperature in the friction area also shows a very similar course, while the differences between the tested friction pairs, depending on the engine oil used, are much smaller than those calculated in the friction force $(\max 4 \%)$. In the case of the $15 \mathrm{MPa}$ load, the temperature value for both used engine oils is identical and amounts to $98^{\circ} \mathrm{C}$ (Figure 6).

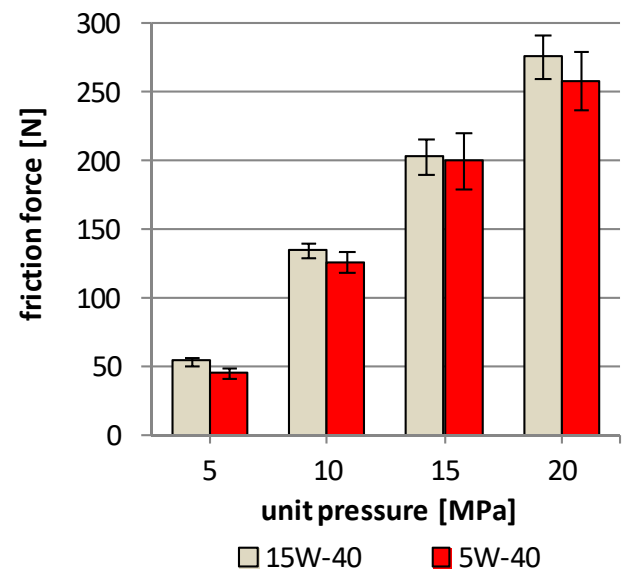

(a)

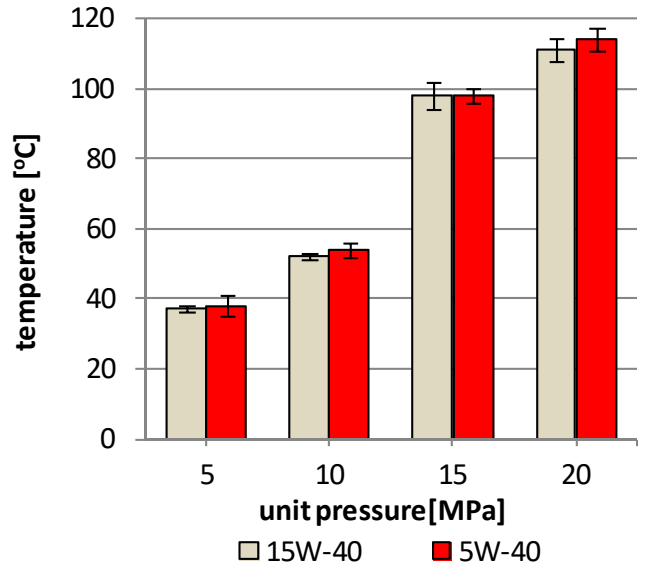

(b)

Figure 6. Friction forces (a) and temperature in friction area (b) vs unit pressure (at $100 \mathrm{rpm}$ and after $500 \mathrm{~s})$.

The analysis of wear of the friction pair elements makes it possible to determine the durability of the friction pair, which allows to determine the period of correct operation of the entire device, as well as periods of periodic inspections and replacement of consumables.

The ring samples with the laser borided surface layer did not show the measurable linear wear, but it was possible to observe the intense wear process of the SAE-48 bearing alloy. The wear of the SAE-48 bearing alloy in the friction pair lubricated with $5 \mathrm{~W}-40$ synthetic oil was higher than the in the friction pair lubricated with 15W-40 mineral oil, at the load 10-20 MPa (Figure 7). The wear of the bearing alloys increases with the pressure increase in the contact area between the surface layers of both elements of the friction pairs. The difference in wear of the alloy ranges from a few percent (at the load of $20 \mathrm{MPa}$ ) to several percent (at the load of 10-15 MPa). At the pressure of $5 \mathrm{MPa}$, the wear of SAE-48 alloy was lower by $22 \%$. In the friction pair lubricated with $5 \mathrm{~W}-40$ synthetic oil.

The behavior of a lubricant under scuffing conditions determines the areas in which the oil retains its properties, enabling the separation of the lubricated surface layers of the cooperating elements of the friction pair. During the tests on the T-02U tester, two loads can be registered: one marking the beginning of the scuffing area and the other, the so-called limiting pressure of seizure. Limiting pressure of seizure depends on the load at which the balls seize and the average value of the wear-scar diameters measured on the stationary balls. 


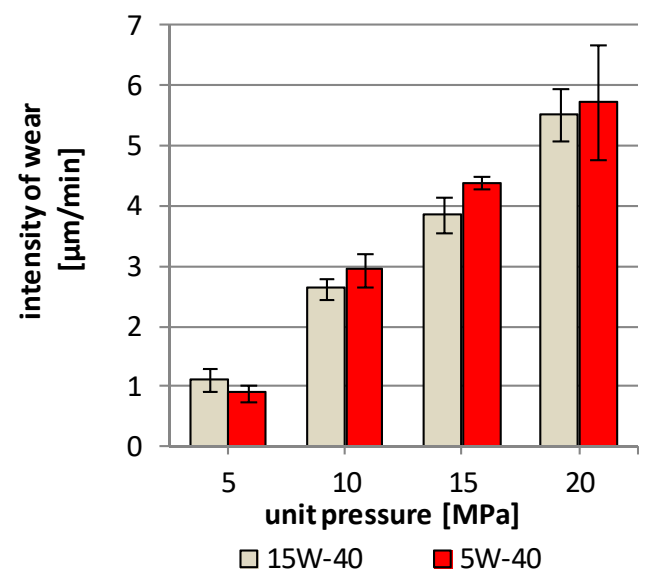

Figure 7. Intensity of wear of SAE-48 bearing alloy during lubrication by engine oils (at $100 \mathrm{rpm}$ ).

Measurements of the seizing load of the used and unused $15 \mathrm{~W}-40$ and $5 \mathrm{~W}-40$ engine oils show a reduction in the seizure resistance of the oil used during the wear tests of the friction pair, as compared to the unused oil (Figure 8). In the tests carried out at the temperature of $40^{\circ} \mathrm{C}$, it can be observed that unused $5 \mathrm{~W}-40$ oil shows the highest resistance to scuffing, while at the temperature of $100{ }^{\circ} \mathrm{C}$, both unused oils show similar values. After the cooperation, a significant reduction in resistance to scuffing of the $5 \mathrm{~W}-40$ oil is observed at $40{ }^{\circ} \mathrm{C}(13 \%)$, and for the $15 \mathrm{~W}-40$ oil, it decreases to $4 \%$. At the temperature of $100{ }^{\circ} \mathrm{C}$, the seizing load of $5 \mathrm{~W}-40$ oil is higher than that of $15 \mathrm{~W}-40$ oil, while the value of the $5 \mathrm{~W}-40$ oil seizing load is similar to the scuffing load of the unused oil.

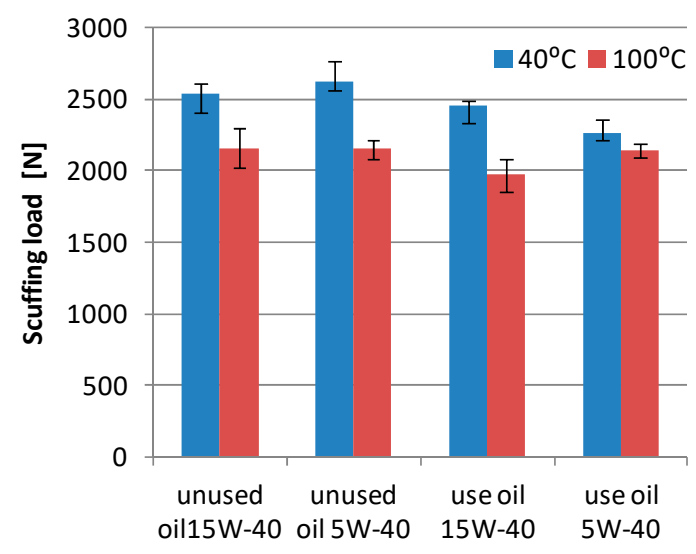

Figure 8. Scuffing load of the unused and used oil; $15 \mathrm{~W}-40$ and $5 \mathrm{~W}-40$.

The seizure load measurements for the tested oils show significant differences and it can be concluded that the $15 \mathrm{~W}-40$ oil shows higher load values than the $5 \mathrm{~W}-40$ oil (Figure 9). In the case of $15 \mathrm{~W}-40$ oil, the load values for used and unused oils are similar at $100^{\circ} \mathrm{C}$. On the other hand, at $40{ }^{\circ} \mathrm{C}$ the load is lower than that for the used oil. The examination of the $5 \mathrm{~W}-40$ oil shows a much greater decrease in the seizure load at $100{ }^{\circ} \mathrm{C}$, which is $11 \%$, and at $40{ }^{\circ} \mathrm{C}$, the seizure load value is similar.

The pressure of seizure shows a significant deterioration in the performance properties of the tested engine oils, which may have been caused by contamination of the oil with wear products and a reduction in the amount of anti-seizure additives in the oil. In the conditions of friction with limited lubrication in the friction area, the anti-seizure additives contained in the engine oil are responsible for the formation of boundary layers preventing seizure, which leads to their wear. On the other hand, stabilization or slight increases in the scuffing load can be explained by the migration of boron, exhibiting lubricating properties, into the oil. Another factor is the decrease in the amount of other 
additives refined from engine oils, which in the new oils cause the degeneration of the lubricating properties (viscosity modifiers, corrosion or rust inhibiting, detergent additives).

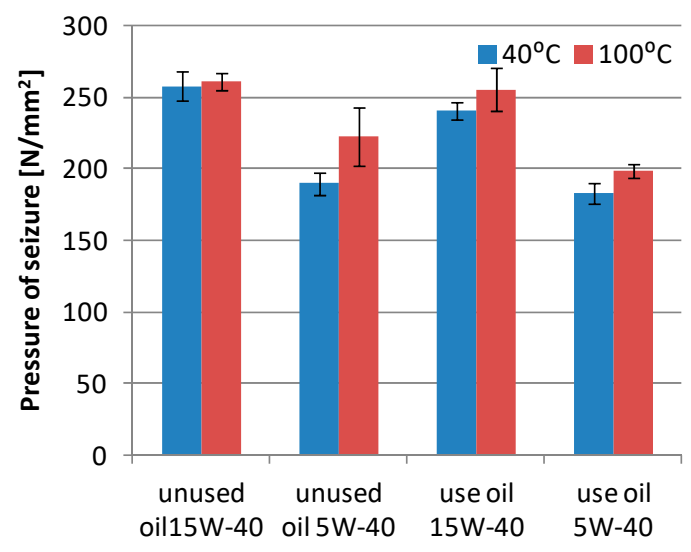

Figure 9. Pressure of seizure of the unused and used oil; $15 \mathrm{~W}-40$ and $5 \mathrm{~W}-40$.

An observation of the sliding surface of SAE-48 bearing alloy samples after wear tests shows non-uniformity of the friction surface. On the surface of the bearing alloy, there are areas of the surface layer with significant deformation, which results from the variable hardness of the laser treatment layer and the lines formed on it, resulting from the arrangement of overlapping traces of the laser beam (Figure 10). In these areas, significant damage to the sliding layer of the bearing alloy can also be observed-cracks and flaking. The maps of the elements in the designated friction areas show significant differences in the distribution of the selected elements $\mathrm{Cu}, \mathrm{Pb}, \mathrm{S}, \mathrm{Mo}$ and $\mathrm{B}$ (Figure 11).
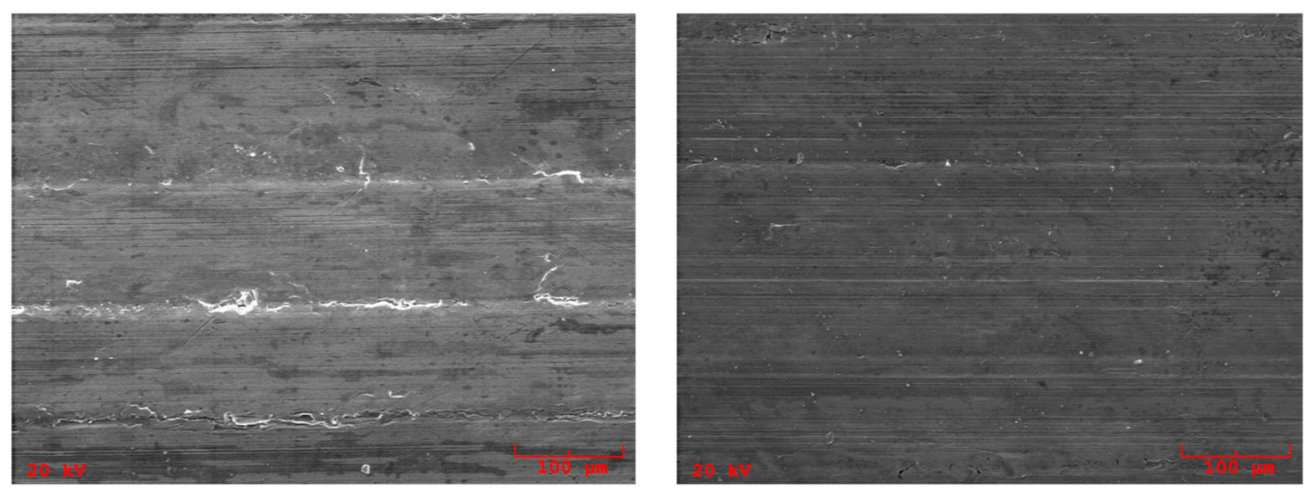

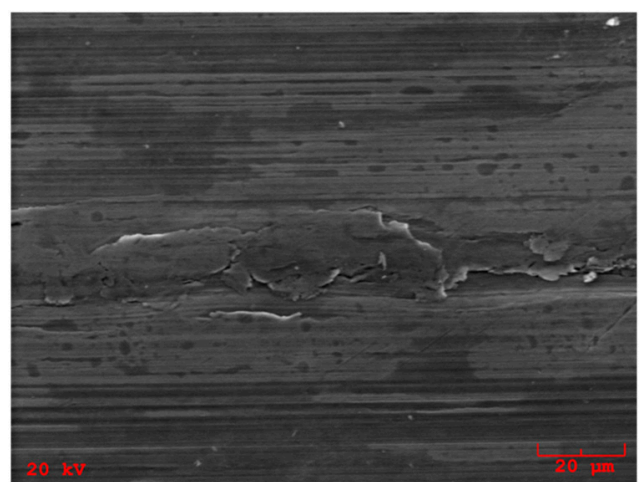

(a)

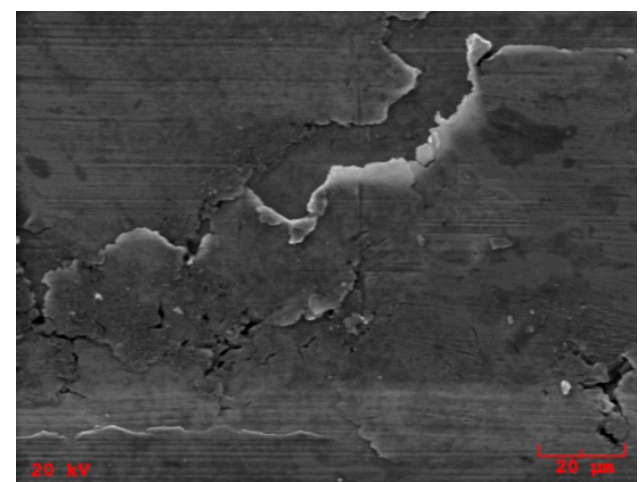

(b)

Figure 10. Micrographs of SAE-48 bearing after tests; (a) 15W-40 engine oil; (b) 5W-40 engine oil. 
a)

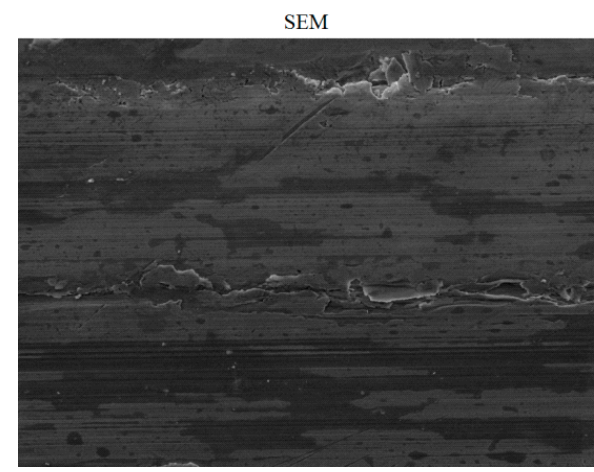

$\mathrm{Cu}$

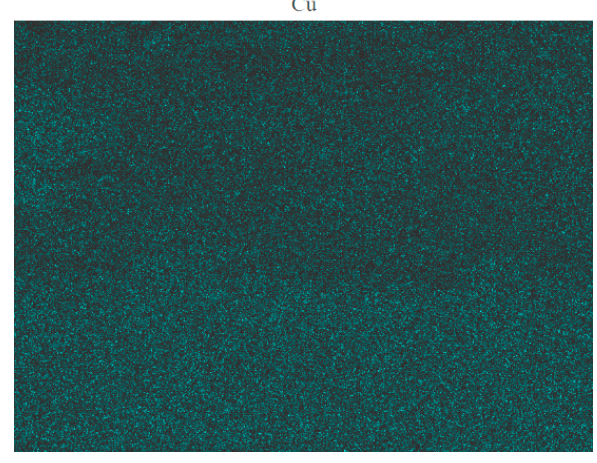

$\mathrm{Pb}$

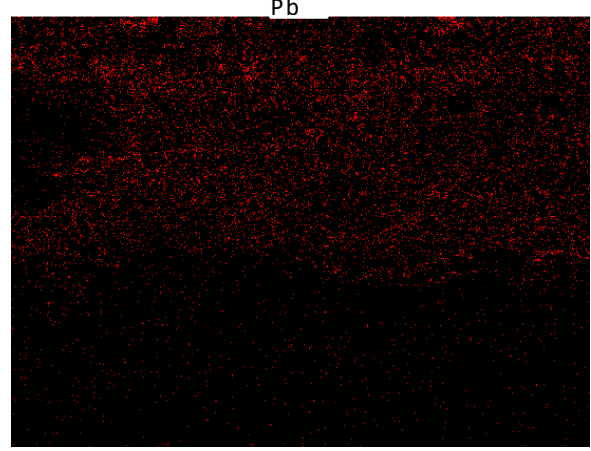

s

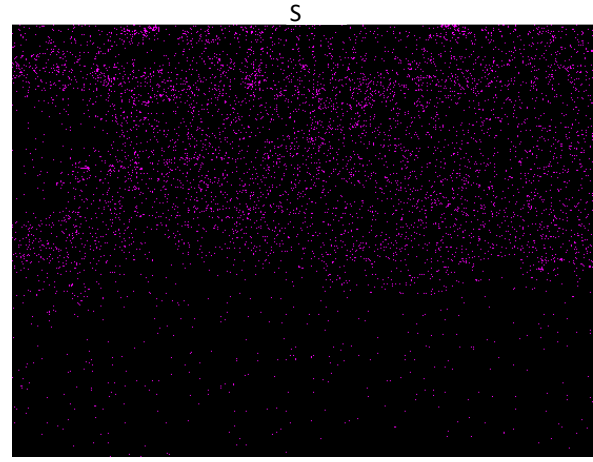

b)

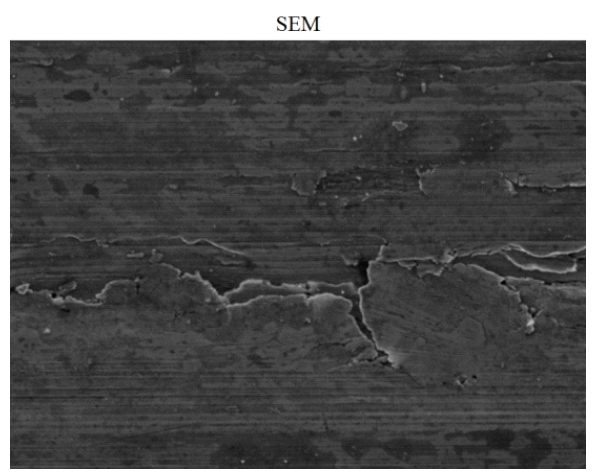

$\mathrm{Cu}$

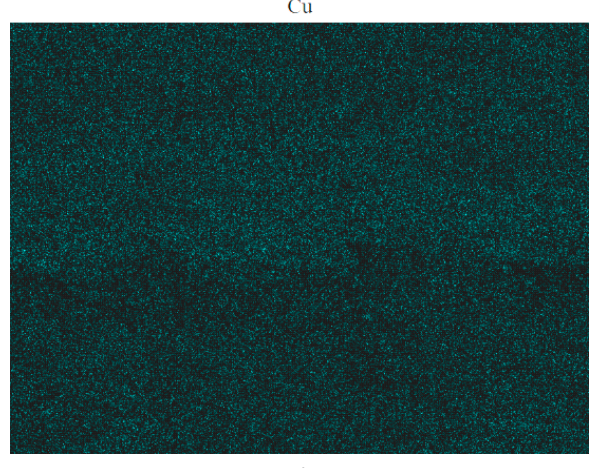

$\mathrm{Pb}$

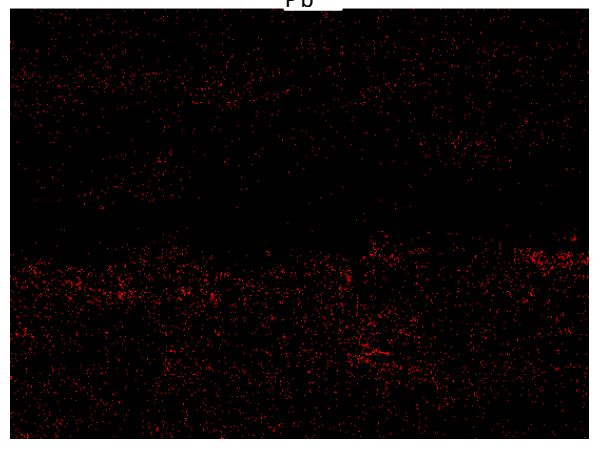

S

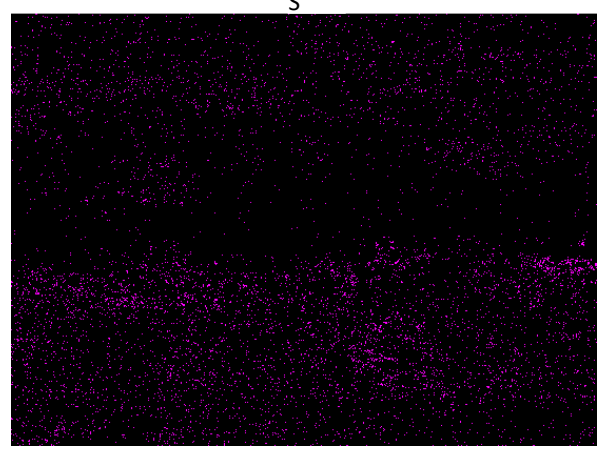

Figure 11. Cont. 

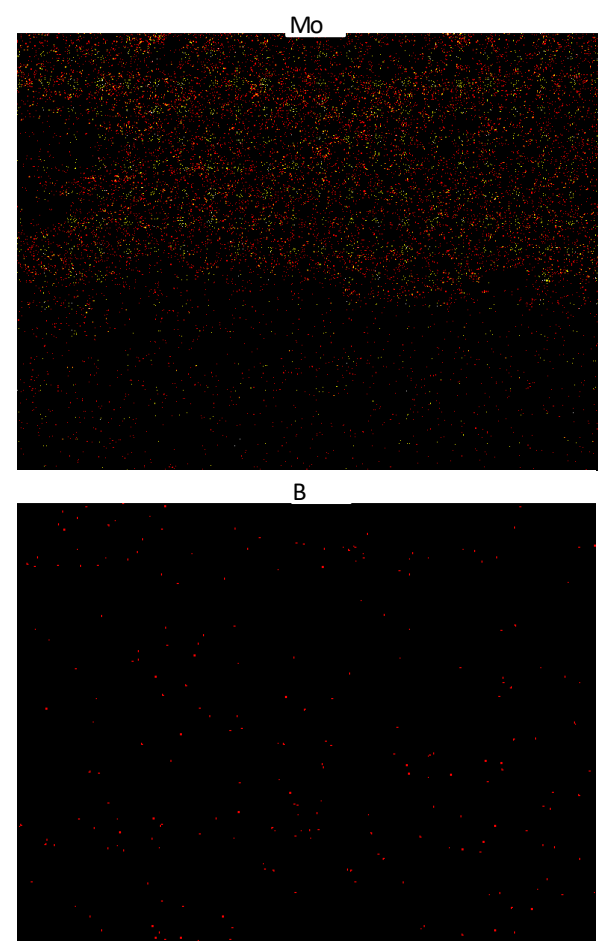

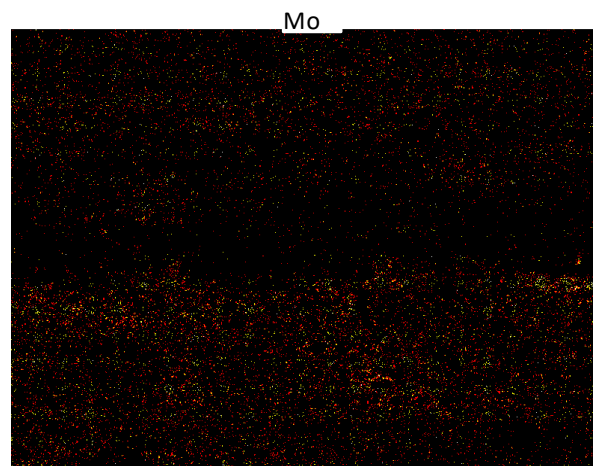

B

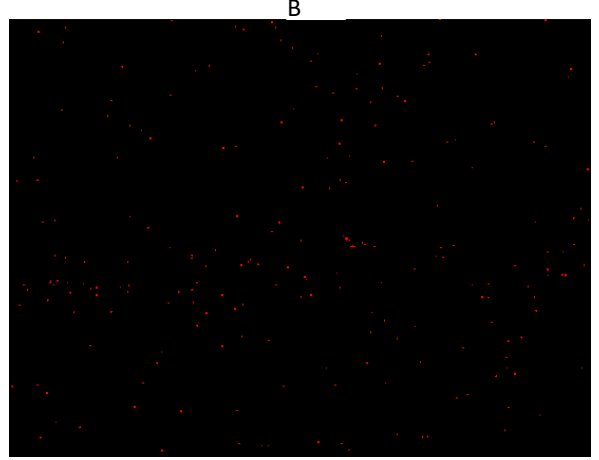

Figure 11. Maps of the distribution of elements in the surface layer SAE-48 bearing alloy; (a) 15W-40 engine oil, (b) 5W-40 engine oil.

An observation of the base elements of the SAE- 48 bearing alloy shows a uniform distribution of $\mathrm{Cu}$, while in the case of $\mathrm{Pb}$, significant differences can be observed, which may result from the migration of lead from the heavily loaded areas to the boundary layers formed in the cooperation area. The analysis of the distribution of $S$ and Mo elements, which are components of the engine oils, also shows their uneven distribution. Intensive wear processes occur in the areas with low presence of the $S$ and Mo elements, which impede the formation of permanent boundary layers containing these elements. The maps of boron distribution shows single atoms in the friction area, which may indicate that in this type of friction pair composition boron transfer is negligible or this element is washed away by the lubricant.

\section{Discussion}

Lubrication of friction pairs with laser remelting structural elements significantly shapes the processes of friction and wear by formation of boundary layers, as a result of the reaction of the surface layers of these elements and the lubricant. The observation of the geometric structure of the surface layers shows a significant reorganization, the effect of which is an increase in the surface roughness of both layers, especially the surface of counter-samples of the SAE-48 bearing alloy [33].

Changes in the Ra parameter show a comprehensive picture of the surface, and the changes in the surface roughness result mainly from the adaptation of both surface layers of the cooperating elements to the specific load conditions of the friction pair. Changes in this parameter significantly affect the load-bearing capacity of the operating surface layers formed in the process of friction. The $+\mathrm{Rz}$ and Sm parameters are parameters that allow the assessment of the local surface unevenness field, and significant changes in their size allow for the identification of changes that arise as a result of drawing, grooves, micro-cutting to protruding surface irregularities or hard wear products occurring in the area of friction or grafting processes occurring as a result of the disappearance of the lubricating layer. These changes result from the processes of rapid destruction of the existing lubricating layers or difficulties in shaping them as a result of friction processes and direct contact of the cooperating layers of the friction pair elements [34]. The unfavorable effect of the laser borided layer may be the 
result of the variable hardness of these surface layers, which is the result of a specific method of its shaping, by overlapping successive laser beam (Figure 10). The observation of the course of the friction coefficient shows that low unit pressures influence the shaping of favorable lubrication conditions, and the system changes the existing geometric structures of both elements into a composition ensuring the most favorable cooperation conditions. The resulting structure provides the given pair with optimal functionality, caused by the creation of stable operational surface layers on both elements of the friction pair $[35,36]$.

The friction and wear processes taking place in the contact area of the sliding pairs depend on unit pressure between cooperating surface layers, microstructural changes of surface layer, chemical reactions between materials, material transformation and material properties variation in surface layers $[33,37,38]$. The wear of bearing alloy is mainly caused by the hard areas in the surface layer of the second material and hard wear particles, which leads to the interaction between the two surface layers and a more intense abrasion of the softer material $[37,38]$. Also, an increase in roughness of the harder material results in an increase in the wear particles detached from the softer material [33]. The hard wear products created in the friction process induce chipping, slicing and grinding, which intensify the wear process [36,39].

During operation, engine oil changes its properties and accumulates impurities, which worsens the lubrication conditions and increases the intensity of wear processes. The lubrication process can remove wear products from the friction area. However, as a result of tribochemical reactions, corrosion processes, cavitation wear, or fatigue wear may occur, the latter caused by dynamic changes in the pressure in the friction area. The assessment of the phenomena is complex and only on the basis of the surface observation of the elements can it be concluded that the oil affects the processes occurring in the contact area.

\section{Conclusions}

Based on the experimental test, the following conclusions can be drawn:

1. The surface roughness of the SAE-48 bearing alloy and laser borided ring specimen shows tendencies to increase and a greater change was observed in the pairs lubricated with $5 \mathrm{~W}-40$ engine oil.

2. Friction force in the pair lubricated with the $15 \mathrm{~W}-40$ engine oil is considerably higher than in the pair lubricated with the $5 \mathrm{~W}-40$ oil, and temperature in the friction area for both tested oils is of a comparable value level.

3. The application of the $5 \mathrm{~W}-40$ oil in the sliding pair with the laser borided surface layer causes a significant increase of wear of the SAE- 48 bearing alloy, together with the increase of unit load in the friction area.

4. The processes of wear lead to the destruction of engine oil and the deterioration of their resistance to scuffing, especially during the operation under low temperature.

5. Lubrication of the friction pair with laser borided surface layer with the $15 \mathrm{~W}-40$ oil is more advantageous because it causes smaller changes in the geometrical structure of the cooperating surface layers, lower friction pair starting resistance and lower wear at a comparable temperature in the friction area.

Author Contributions: Conceptualization, J.L. and W.S.-S.; methodology, J.L., W.S.-S., P.W., E.Z. and K.M.; formal analysis, J.L., W.S.-S., P.W., E.Z. and K.M.; investigation, J.L., W.S.-S. and K.M.; resources, P.W. and E.Z.; data curation, P.W. and E.Z.; writing - original draft preparation, J.L., W.S.-S., P.W., E.Z. and K.M.; writing and editing, J.L.; supervision, J.L. All authors have read and agreed to the published version of the manuscript.

Funding: This research received no external funding.

Conflicts of Interest: The authors declare no conflict of interest. 


\section{References}

1. Yu, J.; Song, B. Effects of heating time on the microstructure and properties of an induction cladding coating. Results Phys. 2018, 11, 212-218. [CrossRef]

2. Makuch, N.; Dziarski, P.; Kulka, M.; Piasecki, A.; Tuliński, M.; Majchrowski, R. Influence of niobium and molybdenum addition on microstructure and wear behavior of laser borided layers produced on Nimonic 80A alloy. Trans. Nonferrous Met. Soc. China 2019, 29, 322-337. [CrossRef]

3. Sui, Q.; Zhou, H.; Bao, H.; Zhang, P.; Yuan, Y.; Meng, C. Wear behavior of quenched iron with various shapes and unit processed through two step laser alloying of C powder. Opt. Laser Technol. 2018, 104, $103-111$. [CrossRef]

4. Liu, Q.; Chen, C.; Zhang, M. Effect of heat treatments on the microstructural evolution and tribological behaviors of a NiCrSiB/Y2O3 alloy fabricated by laser additive manufacturing. Mater. Character. 2020, 165, 110401. [CrossRef]

5. Zhang, D.; Cui, X.; Jin, G.; Feng, X.; Lu, B.; Song, Q.; Yuan, C. Effect of in-situ synthesis of multilayer graphene on the microstructure and tribological performance of laser cladded Ni-based coatings. Appl. Surf. Sci. 2019, 495, 143581. [CrossRef]

6. Xu, X.; Lu, H.F.; Luo, K.Y.; Yao, J.H.; Xu, L.Z.; Lu, J.Z.; Lu, Y.F. Mechanical properties and electrochemical corrosion resistance of multilayer laser cladded Fe-based composite coatings on 4Cr5MoSiV1 steel. J. Mater. Proc. Tech. 2020, 284, 116736. [CrossRef]

7. Yan, S.X.; Dong, S.Y.; Xu, B.S.; Wang, Y.J.; Ren, W.B.; Fang, J.X. Effect of preheating temperature on microstructure and property of laser clad ni-based alloy coating on gray cast iron substrate. J. Mater. Eng. 2015, 43, 30-36.

8. Zhou, S.F.; Dai, X.Q.; Zheng, H.Z. Microstructure and wear resistance of Fe-based WC coating by multi-track overlapping laser induction hybrid rapid cladding. Opt. Laser. Technol. 2012, 44, 190-197. [CrossRef]

9. Mohan, D.G.; Gopi, S. Induction assisted friction stir welding: A review. Aust. J. Mech. Eng. 2020, 1, 119-123. [CrossRef]

10. Zhang, S.; Wu, C.L.; Zhang, C.H.; Guan, M.; Tan, J.Z. Laser surface alloying of FeCoCrAlNi high entropy alloy on 304 stainless steel to enhance corrosion and cavitation erosion resistance. Opt. Laser Technol. 2016, 84, 23-31.

11. Adebiyi, D.I.; Popoola, A.P.I. Mitigation of abrasive wear damage of Ti-6Al-4V by laser surface alloying. Mater. Des. 2015, 74, 67-75. [CrossRef]

12. Yan, H.; Wang, A.; Xiong, Z.; Xu, K.; Huang, Z. Microstructure and wear resistance of composite layers on a ductile iron with multicarbide by laser surface alloying. Appl. Surf. Sci. 2010, 256, 7001-7009. [CrossRef]

13. Li, J.; Liu, H.; Li, G. Surface performance and physical properties of nanoscale ceramics reinforced laser alloying composite coatings. Compos. Part B 2014, 57, 86-90. [CrossRef]

14. Prince, M.; Arjun, S.L.; Surya, R.; Gopalakrishnan, P. Experimental Investigations on the Effects of Multicomponent Laser Boriding on steels. Mater. Today Proc. 2018, 5, 25276-25284. [CrossRef]

15. Klopotov, A.A.; Ivanov, Y.F.; Potekaev, A.I.; Abzaev, Y.A.; Kalashnikov, M.P.; Chumaevskii, A.V.; Volokitin, O.G.; Teresov, A.D.; Vlasov, V.A.; Klopotov, V.D. The use of low-temperature plasma in a combined technology for the formation of wear-resistant boron-containing coatings. Surf. Coat. Technol. 2020, 389, 125576.

16. Misra, D.; Dhakar, B.; Anusha, E.; Shariff, S.M.; Mukhopadhyay, S.; Chatterje, S. Evaluation of nanomechanical and tribological properties of laser surface alloyed boride-nitride-carbide ceramic matrix composite coatings. Cer. Int. 2018, 44, 17050-17061. [CrossRef]

17. Hu, G.; Meng, H.M.; Liu, J.Y. Microstructure and corrosion resistance of induction melted Fe-based alloy coating. Surf. Coat. Technol. 2014, 251, 300-306. [CrossRef]

18. Gök, M.S.; Küçük, Y.; Erdoğan, A.; Öge, M.; Kanca, E.; Günen, A. Dry sliding wear behavior of borided hot work tool steel at elevated temperatures. Surf. Coat. Technol. 2017, 328, 54-62. [CrossRef]

19. Telasang, G.; Majumdar, J.D.; Padmanabham, G.; Manna, I. Wear and corrosion behaviour of laser surface engineered AISI H13 hot working tool steel. Surf. Coat. Technol. 2015, 261, 69-78. [CrossRef]

20. Sashank, S.; Dinesh Babu, P.; Marimuthu, P. Experimental studies of laser borided low alloy steel and optimization of parameters using response surface methodology. Surf. Coat. Technol. 2019, 363, 255-264. 
21. Wei, X.; Chen, Z.; Zhong, J.; Wang, L.; Hou, Z.; Zhang, Y.; Tan, F. Facile preparation of nanocrystalline $\mathrm{Fe}_{2} \mathrm{~B}$ coating by direct electrospark deposition of coarse-grained $\mathrm{Fe}_{2} \mathrm{~B}$ electrode material. J Alloys Comp. 2017, 717, 31-40. [CrossRef]

22. Aguilar-Hurtado, J.Y.; Vargas-Uscategui, A.; Paredes-Gil, K.; Palma-Hillerns, R.; Tobar, M.J.; Amado, J.M. Boron addition in a non-equiatomic $\mathrm{Fe}^{50} \mathrm{Mn}_{30} \mathrm{Co}_{10} \mathrm{Cr}_{10}$ alloy manufactured by laser cladding: Microstructure and wear abrasive resistance. Appl. Surf. Sci. 2020, 515, 146084. [CrossRef]

23. Kulka, M.; Mikołajczak, D.; Makuch, N.; Dziarski, P.; Miklaszewski, A. Wear resistance improvement of austenitic 316L steel by laser alloying with boron. Surf. Coat. Technol. 2016, 291, 292-313. [CrossRef]

24. Kulka, M.; Makuch, N.; Dziarski, P.; Mikołajczak, D.; Przestacki, D. Gradient boride layers formed by diffusion carburizing and laser boriding. Opt. Lasers Eng. 2015, 67, 163-175.

25. Bendoumi, A.; Makuch, N.; Chegroune, R.; Kulka, M.; Keddam, M.; Dziarski, P.; Przestacki, D. The effect of temperature distribution and cooling rate on microstructure and microhardness of laser re-melted and laser-borided carbon steels with various carbon concentrations. Surf. Coat. Technol. 2020, 387, 125541. [CrossRef]

26. Günen, A.; Kanca, E.; Çakir, H.; Karakaş, M.S.; Göke, M.S.; Küçük, Y.; Demir, M. Effect of borotitanizing on microstructure and wear behavior of Inconel 625. Surf. Coat. Technol. 2017, 311, 374-382. [CrossRef]

27. Kulka, M.; Dziarski, P.; Makuch, N.; Piasecki, A.; Miklaszewski, A. Microstructure and properties of laser-borided Inconel 600-alloy. Appl. Surf. Sci. 2013, 284, 757-771. [CrossRef]

28. Dziarski, P.; Kulka, M.; Mikołajczak, D.; Makuch, N. Corrosion resistance of laser-borided Inconel 600 alloy. Inżyn. Mater. 2017, 3, 149-156.

29. Makuch, N.; Piasecki, A.; Dziarski, P.; Kulka, M. Influence of laser alloying with boron and niobium on microstructure and propertiesof Nimonic 80A-alloy. Opt. Laser. Technol. 2015, 75, 229-239. [CrossRef]

30. Eder, S.J.; Ielchici, C.; Krenn, S.; Brandtner, D. An experimental framework for determining wear in porous journal bearings operated in the mixed lubrication regime. Tribol. Intern. 2018, 123, 1-9.

31. García, A.; Cadenas, M.; Fernandez, M.R.; Noriega, A. Tribological effects of the geometrical properties of plasma spray coatings partially melted by laser. Wear 2013, 305, 1-7. [CrossRef]

32. Habib, K.A.; Cano, D.L.; Heredia, J.A.; Mira, J.S. Effect of post coating technique on microstructure; microhardness and the mixed lubrication regime parameters of thermally sprayed NiCrBSi coatings. Surf. Coat. Technol. 2019, 358, 824-832. [CrossRef]

33. Akchurin, A.; Bosman, R.; Lugt, P.M.; Drogen, M. Analysis of wear particles formed in boundary-lubricated sliding contacts. Tribol. Lett. 2016, 63, 16. [CrossRef]

34. Nehme, G.; Mourhatch, R.; Aswath, P.B. Effect of contact load and lubricant volume on the properties of tribofilms formed under boundary lubrication in a fully formulated oil under extreme load conditions. Wear 2010, 268, 1129-1147. [CrossRef]

35. Schouwenaars, R.; Jacobo, V.H.; Ortiz, A. Microstructure aspect of wear in soft tribological alloys. Wear 2007, 263, 727-735. [CrossRef]

36. Dudek, K.; Szczypinski-Sala, W.; Lubas, J. Influence of laser boriding on the friction and wear of sliding couples with bearing alloys. Surf. Rev. Lett. 2020, 27, 1950084.

37. Piasecki, A.; Kotkowiak, M.; Makuch, N.; Kulka, M. Wear behavior of self-lubricating boride layers produced on Inconel 600-alloy by laser alloying. Wear 2019, 426, 919-933. [CrossRef]

38. Dziedzic, A.; Lubas, J.; Bochnowski, W.; Adamiak, S. The mechanisms of tribological wear in lubricated sliding bearings composed of soft bearing alloys with borided steel. Proc. Inst. Mechan. Eng. Part J J. Eng. Tribol. 2016, 230, 350-363. [CrossRef]

39. Lubas, J. Practical application of boron-modified sliding pairs in I.C. engine. Tribol. Int. 2010, 43, $2046-2050$. [CrossRef]

Publisher's Note: MDPI stays neutral with regard to jurisdictional claims in published maps and institutional affiliations. 